\title{
PEMASARAN KOPI PADA ERA KE TIGA DI KABUPATEN KUNINGAN
}

\section{COFFEE MARKETING IN THE THIRD ERA IN KUNINGAN REGENCY}

\author{
Wachdijono*, Akhmad Jaeroni \\ Program Studi Agribisnis Fakultas Pertanian, Universitas Swadaya Gunung Jati (UGJ) Cirebon \\ Jalan Raya Pemuda 32 Cirebon 45132 \\ *E-mail: wadiono1113@gmail.com \\ (Diterima 15-04-2021; Disetujui 03-06-2021)
}

\begin{abstract}
ABSTRAK
Pemasaran kopi pada era ketiga ditandai dengan gejala-gejala yang mengarah pada sinergitas subsistem-subsistem dalam agribisnis kopi. Penelitian ini bertujuan untuk mendeskripsikan indikator-indikator pemasaran kopi pada era ketiga di Kabupaten Kuningan. Penelitian menggunakan metode deskriptif. Populasi terdiri atas empat unsur, yaitu: petani kopi, pengolah kopi, penyaji kopi dan konsumen kopi. Besar sampel ditentukan secara sengaja, yaitu: petani kopi sebanyak 60 orang, pengolah kopi 30 orang, penyaji kopi 15 orang, dan konsumen kopi 50 orang. Waktu penelitian selama bulan Agustus-November 2020. Hasil penelitian menyimpulkan bahwa pemasaran kopi pada era ke tiga di Kabupaten Kuningan belum tersinergi diantara subsistem sehingga indikator-indikatornya belum terpenuhi secara optimal, yang mengakibatkan kemanfaatan/peluang laba yang ada dalam agribisnis kopi ini belum diperoleh secara proporsional. Untuk itu diperlukan sinergitas yang lebih kuat diantara subsistem agribisnis yang diprakarsai oleh Dinas Perkebunan setempat.
\end{abstract}

Kata kunci: agribisnis, indikator, kopi, pemasaran era ketiga, sinergitas

ABSTRACT
Coffee marketing in the third era was marked by symptoms that led to the synergy of the subsystems in the coffee agribusiness. This study aims to describe the indicators of coffee marketing in the third era in Kuningan Regency. This research uses descriptive method. The population consists of four elements, namely: coffee farmers, coffee processors, coffee presenters and coffee consumers. The sample size was determined intentionally, namely: 60 coffee farmers, 30 coffee processors, 15 coffee presenters and 50 coffee consumers. Research time during AugustNovember 2020. The results of the study conclude that the marketing of coffee in the third era in Kuningan Regency has not been synergized among the subsystems so that the indicators have not been fulfilled optimally, which results in the benefits/profit opportunities that exist in coffee agribusiness that have not been obtained proportionally. For this reason, a stronger synergy is needed between the agribusiness subsystems initiated by the local Plantation Service.

Keywords: agribusiness, indicators, coffee, synergy, third era marketing

\section{PENDAHULUAN}

Kopi adalah produk pertanian yang dalam satu tahun ini menjadi bahan perbincangan oleh banyak kalangan, terutama: akademisi, praktisi dan pemerintah. Tingginya perhatian kepada kopi, tidak terlepas dari beberapa faktor, antara lain: cita rasa, sejarah, nilai ekonomi, budidaya, kualitas, petani dan industri kopi yang sangat berkembang pada dewasa ini. Selain itu, juga faktor nilai manfaat yang terkandung dalam 
minuman kopi, antara lain: menjaga stamina, menurunkan potensi serangan kanker, mencegah depresi dan parkinson, mencegah alzheimer dan demensia, serta membersihkan saluran pencernaan (Santani, 2018), menimbulkan semangat dalam bekerja, efek segar dan menghilangkan rasa kantuk (Rasmikayati, dkk, 2017), meningkatkan kinerja kognitif yang lebih baik pada kaum wanita tua (Johnson-Kozlow et al, 2002). Pada faktanya, kopi merupakan komoditi penyegar yang dibutuhkan oleh masyarakat dunia, mulai dari desa-desa kecil di pelosok negara hingga kota-kota metropolitan, bahkan menyentuh pusatpusat pariwisata dunia di banyak negara dimana minuman kopi itu sendiri dijadikan sebagai penghangat pertemuan baik di kantor, kampung hingga jamuan internasional (Raharjo, 2012). Namun demikian, setiap pembahasan kopi dimanapun, yang jelas tidak akan terlepas pada aspek pemasarannya. Menurut Santani (2018), pemasaran kopi dibedakan menjadi tiga fase, yaitu: fase pertama (tahun 1890-1960), fase kedua (tahun 1960-1990), dan fase ketiga (tahun 1990-sekarang).

Pemasaran kopi pada era ketiga ditandai dengan fenomena-fenomena, antara lain: banyaknya kedai kopi yang muncul di perbagai daerah, penikmat kopi semakin kritis pada aspek asal-usul dan mutu kopi, serta munculnya kepedulian terhadap kesejahteran petani kopi. Selain itu meminum kopi, tidak hanya untuk merasakan nikmat dan khasiatnya, namun sudah memperhatikan kepada pihak-pihak yang berperan dalam menyajikan minuman kopi berkualitas. Fenomena ini menjadi menarik dikarenakan sub sistem hulu, sub sistem pengolahan dan sub sistem hilir menjadi satu kesatuan perhatian teknis yang tak terpisahkan dalam sistem agribisnis kopi saat ini, khususnya di Indonesia. Pada sisi produksi, Indonesia berpotensi memiliki perkebunan kopi seluas 1,3 juta hektar dan sebagian besar merupakan perkebunan rakyat, selebihnya milik pemerintah dan swasta (Rukmana dan Suyantoro, 2014). Adapun pada sisi konsumsi, pada periode tahun 2011-2017, menunjukkan arah pertumbuhan atau tren yang (International Coffee Organization, n.d.)

Kuningan adalah suatu kabupaten di Provinsi Jawa Barat, yang sebagian penduduknya mengusahakan tanaman kopi sehingga dikenal juga sebagai sentra produksi kopi. Berbagai produksi komoditas perkebunan di Kabupaten Kuningan dapat dilihat pada Tabel 1. 
Tabel 1. Produksi komoditas perkebunan Kabupaten Kuningan tahun 2014

\begin{tabular}{|c|c|c|}
\hline No. & Komoditas & Jumlah Produksi (ton) \\
\hline 1 & Tebu & 377,491 \\
\hline 2 & Kelapa & 344,963 \\
\hline 3 & Kopi & 872,520 \\
\hline 4 & Kapuk & 52,414 \\
\hline 5 & Aren & 26,017 \\
\hline & $\begin{array}{l}\text { Dinas } \mathrm{K} \\
\text { Kabupat }\end{array}$ & $\begin{array}{l}\text { tanan dan Perkebunan } \\
\text { uningan Tahun } 2014\end{array}$ \\
\hline
\end{tabular}

Tabel 1 menjelaskan, produksi kopi menempati urutan terbesar dan sangat berpotensi untuk menjadi produk unggulan daerah. Adanya produk unggulan daerah akan dapat menunjang peningkatan kesejahteraan (melalui peningkatan laba agribisnis kopi) bagi pihak-pihak yang berperan, yaitu: petani, pengolah, penyaji dan kepuasan bagi konsumennya.

Berdasarkan uraian di atas, dapat diambil suatu pola keterkaitan, antar pihak, yaitu: produksi, pengolah, penyaji maupun konsumsi kopi yang memberikan peluang positif (laba) secara bersama dan terbuka dalam konsep pemasaran kopi pada era ketiga ini. Oleh karenanya menjadi hal yang sangat menarik untuk dilakukan suatu penelitian mengenai analisis pemasaran kopi pada era ketiga di Kabupaten Kuningan. Pemasaran sendiri didefinisikan sebagai rangkaian kegiatan bisnis yang bertujuan memberi kepuasan konsumen melalui produk yang dibelinya, sehingga dalam pemasaran ada aktifitas produksi, pengolahan, penyaji dan komsumsi (Kotler, 2000; Tjiptono, 2008).

Penelitian sebelumnya yang relevan dengan penelitian ini, antara lain: Kustiari (2007), menyatakan pangsa pasar kopi Indonesia di pasar-pasar tradisional cenderung menurun, oleh karena itu diperlukan upaya-upaya antara lain mendiversifikasi pasar tujuan dan produk kopi serta meningkatkan ekspor kopi olahan; Prakosa menyimpulkan persepsi kualitas, citra negara asal, dan kepercayaan memiliki keterkaitan dengan minat beli produk kopi gelombang ketiga; Pratiwi, et al (2019) menyimpulkan ada beberapa lembaga pemasaran kopi, yaitu: petani, pedagang pengumpul, pedagang besar, pengecer dan koperasi; Alfirahmi (2019) menyimpulkan marketing 4.0 yang menyatukan system offline dengan online menjadi jawaban bagi gerai kopi untuk semakin menggaet kaum urban untuk mengenal dan mengkonsumsi kop; Wachdijono et al (2019) menyimpulkan preferensi konsumen kopi pada era revolusi industry $4.0 \quad$ lebih mempertimbangkan pada atribut merk; Rosiana (2020) menyimpulkan petani kopi di lima sentra produksi utama Indonesia menjual kopi dalam bentuk 
kopi asalan yang secara umum menjual ke pedagang pengumpul.

Penelitian ini bertujuan untuk mendeskripsikan indikator-indikator pada pemasaran kopi pada era ketiga di Kabupaten Kuningan, yaitu: 1) Jenis kopi yang dipasarkan; 2) Teknis budidaya kopi; 3) Jumlah produksi kopi; 4) Pola saluran pemasaran; 5) Proporsi pemasaran; 6) Pengolahan kopi; 7) Aneka penyajian kopi; 8) Kepedulian konsumen petani kopi; 9) Jumlah petani kopi; dan 10) Tumbuhnya kedai-kedai kopi. Hasil penelitian bermanfaat dalam menghasilkan implikasi kebijakan kepada Pemerintah Kabupaten Kuningan Provinsi Jawa Barat terutama pada sub sektor perkebunan.

\section{METODE PENELITIAN}

Lokasi penelitian ditentukan secara sengaja yaitu di Kecamatan Subang, Darma, Mandirancan dan Kota Kuningan Kabupaten Kuningan Provinsi Jawa Barat dengan alasan bahwa di ketiga kecamatan tersebut merupakan daerah sentra produksi kopi dan kota Kuningan sebagai daerah pemasarannya. Penelitian dilaksanakan pada bulan JuliNovember 2020. Jenis penelitian yang digunakan adalah deskriptif dengan teknik pendekatan survai. Sugiyono
(2015) menjelaskan, penelitian deskriptif memiliki pengertian yang lebih luas dan ciri khas yakni memusatkan diri pada masalah masa sekarang dan aktual dan data yang diperoleh disusun, dijelaskan dan dianalisis.

Untuk mencapai tujuan penelitian yang diharapkan, maka ditetapkan definisi operasional terhadap variablevariabel/sub variabel/indikator yang diteliti beserta konsep pengukurannya. Adapun variabel utamanya adalah pemasaran yang didefinisikan sebagai sejumlah kegiatan bisnis yang ditujukan untuk memberi kepuasan dari barang atau jasa yang dipertukarkan kepada konsumen. Oleh karena itu, dalam konsep pemasaran mencakup aspek produksi, aspek distribusi dan aspek konsumsi yang saling terkait, sehingga yang menjadi sub-sub variabel/indikatornya, yaitu:

1) Jenis kopi yang dipasarkan adalah jenis kopi yang dibudidaya dan bentuk-bentuk produk kopi yang dipasarkan kepada konsumen, yaitu jenis kopi terdiri atas: kopi Robusta, Arabika dan Liberika, sedangkan bentuk-bentuk produk kopi terdiri atas: biji, bubuk, gabah dan biji sangrai.

2) Teknis budidaya kopi, adalah cara bercocok tanaman kopi yang sedang 
dilakukan oleh petani berdasarkan Good Agricultural Practices (GAP).

3) Jumlah produksi kopi adalah jumlah kopi setiap panen, yang diukur dengan $\mathrm{kg} /$ panen/tahun/petani.

4) Pola saluran pemasaran adalah model-model saluran yang dilalui produk kopi dari produsen ke konsumen akhir, yang terdiri atas: menjual langsung, menjual melalui tengkulak/agen dan media online.

5) Proporsi segmen pemasaran kopi adalah jumlah kopi yang dipasarkan pada tiap segmen pasar (lokal dan non lokal) yang dinyatakan dalam persentase $(\%)$.

6) Pengolahan kopi adalah tindakan/cara untuk mengubah kopi biji segar menjadi bahan setengah jadi atau bahan jadi, yang terdiri atas: cara tradisional, modern dan tradisional-modern.

7) Aneka penyajian kopi adalah suatu aktifitas untuk menyajikan minuman kopi dengan berbagai cara, yang terdiri atas: latte art, V-60, Vietnam Drip, kopi tubruk, manual dan mix blended.

8) Kepedulian konsumen kepada petani kopi adalah komentar-komentar atau sikap-sikap konsumen terhadap kondisi petani kopi pada aspek asalusul kopi dan kualitasnya, yang terdiri atas: peduli, cukup peduli, sangat peduli dan tidak peduli.

9) Jumlah petani kopi adalah ukuran hasil menghitung jumlah petani kopi pada saat penelitian dibanding dengan lima tahun sebelumnya.

10) Tumbuhnya kedai-kedai kopi adalah banyaknya kedai kopi (coffee shop) yang berdiri dalam rentang waktu lima tahun terakhir ini.

Untuk teknis operasionalnya, maka definisi operasional dan konsep pengukuran variabel di atas dapat dirangkum dalam Tabel 2.

Tabel 2. Operasionalisasi variabel, sub variabel/indikator dan skala pengukuran

\begin{tabular}{|c|c|c|}
\hline Variabel & Sub variabel/Indikator & Skala pengukuran \\
\hline \multirow{10}{*}{$\begin{array}{l}\text { Pemasaran kopi pada era } \\
\text { ketiga di Kabupaten } \\
\text { Kuningan Provinsi Jawa } \\
\text { Barat }\end{array}$} & 1. Jenis kopi yang dipasarkan & Nominal \\
\hline & 2. Teknis budidaya kopi & Nominal \\
\hline & 3. Jumlah produksi kopi & Rasio \\
\hline & 4. Pola saluran pemasaran & Nominal \\
\hline & 5. Proporsi pemasaran segmen kopi & Rasio \\
\hline & 6. Pengolahan kopi & Nominal \\
\hline & 7. Aneka penyajian minuman kopi & Nominal \\
\hline & $\begin{array}{l}\text { 8. Kepedulian konsumen terhadap petani (asal-usul } \\
\text { dan kualitas kopi) }\end{array}$ & Nominal \\
\hline & 9. Jumlah petani kopi & Rasio \\
\hline & 10. Tumbuhnya kedai-kedai kopi & Rasio \\
\hline
\end{tabular}


Populasi dalam penelitian ini terdiri empat unsur, yaitu: petani kopi, pengolah kopi, penyaji kopi dan konsumen kopi. Adapun penentuan besar sampel dilakukan secara sengaja yaitu quota sampling, sehingga sampel untuk petani sebanyak 60 orang, pengolah kopi 30 orang, penyaji kopi 15 orang dan konsumen 50 orang. Teknik pengumpuan data mencakup data primer dan data sekunder. Adapun analisis data dilakukan secara deskriptif, artinya pembahasan yang dilakukan benar-benar hanya memaparkan apa yang terdapat atau terjadi di lapangan. Teknik pengolahan data berdasarkan kaidah-kaidah hitung matematika dan statistika (persentase).

\section{HASIL DAN PEMBAHASAN}

Berdasarkan hasil penelitian, maka pembahasannya akan diuraikan secara deskriptif pada indikator-indikator pemasaran era ke tiga di Kabupaten Kuningan, yaitu: 1) Jenis kopi yang dipasarkan; 2) Teknis budidaya kopi; 3) Jumlah produksi kopi; 4) Pola saluran pemasaran; 5) Proporsi pemasaran; 6) Pengolahan kopi; 7) Aneka penyajian kopi; 8) Kepedulian konsumen petani kopi; 9) Jumlah petani kopi; dan 10) Tumbuhnya kedai-kedai kopi. Adapun pembahasannya sebagai berikut:

\section{A. Jenis Kopi yang Dipasarkan}

Sesuai dengan potensi sumberdaya alam yang ada yaitu daerah pegunungan, maka jenis kopi yang dibudidayakan petani terdiri atas 3 jenis kopi yaitu kopi Robusta, Arabika dan Liberika. 95\% petani menanam kopi jenis Robusta, 5\% petani menanam Arabika dan $2 \%$ menanam Liberika. Sebagian besar petani menanam kopi Robusta, ini selaras dengan hasil penelitian Martauli (2018) yang menyimpulkan jenis kopi Robusta lebih banyak ditanam di Indonesia dari pada jenis kopi Arabika karena produktivitasnya lebih tinggi dan sebagian besar kedua jenis kopi tersebut berasal dari perkebunan rakyat (95,37\%).

Hasil panen kopi yang dijual petani ke pasar sebagian besar (82\%) dalam bentuk green bean (biji kopi), kemudian sebanyak 16\% dipasarkan dalam bentuk buah kopi (cerry) dan dalam bentuk campuran sebanyak $2 \%$. Petani sebagaian besar menjual dalam bentuk green bean ini berbeda dengan hasil penelitian Rosiana (2020) yang menyatakan bahwa petani kopi di lima sentra produksi utama di Indonesia menjual kopi dalam bentuk kopi asalan dikarenakan tidak repot (tidak ada perlakuan khusus) sehingga cepat mendapatkan uang. Dengan perbandingan ini maka petani kopi di 
Kabupaten Kuningan selangkah lebih maju dalam hal penjualan kopi, yaitu sudah dalam bentuk greenbean sehingga secara nilai ekonominya lebih tinggi.

\section{B. Teknis Budidaya Kopi}

Teknik budidaya kopi merupakan tatalaksana budidaya kopi yang dilakukan oleh petani berdasarkan pada Good Agricultural Practices (GAP) atau juga dikenal dengan teknik budidaya kopi untuk memperoleh hasil (produksi) yang optimum (Tim Karya Tani Mandiri, 2010), yang mencakup kegiata-kegiatan sebagaimana dapat dilihat pada Tabel 3 .

Tabel 3. Kegiatan budidaya kopi di Kabupaten Kuningan tahun 2020

\begin{tabular}{|c|c|}
\hline Kegiatan Budidaya & Keterangan \\
\hline 1) Penggunaan bibit unggul & $\begin{array}{l}96 \% \text { petani memakai bibit kopi unggul: Tugu Ijo, Tugu Kuning dan } \\
\text { Ateng }\end{array}$ \\
\hline 2) Penggunaan pupuk dasar & $96 \%$ petani menggunakan pupuk dasar \\
\hline 3) Pengaturan jarak tanam & $100 \%$ petani menerapkan jarak tanam: $2 \mathrm{~m} \times 2 \mathrm{~m}$ dan $3 \mathrm{~m} \times 3 \mathrm{~m}$ \\
\hline 4) Pohon pelindung & $100 \%$ petani telah menggunakan pohon pelindung \\
\hline 5) Penyula & $100 \%$ petani melakukan penyulaman setelah tanaman berumur 1 tahun \\
\hline 6)Pemupukan lanjutan(kompos) & $87 \%$ petani menggunakan pupuk kandang: kambing, ayam dan sapi \\
\hline 7) Pemupukan lanjutan (kimia) & 98 \% petani menggunakan pemupukan kimia: pupuk urea dan TSP \\
\hline 8) Pemangkasan: & $\begin{array}{l}95 \% \text { petani melakukan pemangkasan pada ranting yang tidak } \\
\text { diharapkan }\end{array}$ \\
\hline 9) Penanggulangan gulma: & $100 \%$ petani melakukan penanggulanan gulma \\
\hline $\begin{array}{l}\text { 10) Cara pemetikan panen kopi } \\
\text { (warna buah kopi) }\end{array}$ & $\begin{array}{l}24 \% \text { petani petik kopi warna merah penuh, } 31 \% \text { merah kekuningan } \\
\text { dan } 45 \% \text { warna campuran (pemetikan dilakukan dengan cara vertikal } \\
\text { dan perampasan }\end{array}$ \\
\hline 11) Sortasi hasil panen: & $\begin{array}{l}69 \% \text { petani tidak melakukan grading dan sortasi, } 31 \% \text { melakukan } \\
\text { sortasi ha }\end{array}$ \\
\hline
\end{tabular}

Sumber: Data primer diolah (2020)

Hasil penelitian ini jika dibandingkan dengan hasil penelitian Saragih (2017) terdapat beberapa perbedaan pada aspek teknis budidayan kopi. Adanya perbedaan tersebut sangat wajar karena banyak faktor pula yang menjadi penyebabnya, namun demikian selain ada perbedaa, yang jelas memliki dua kesamaan yaitu bagaimana agribisnis kopi di Indonesia ini terus berkelanjutan dan menguntungkan. Mengenai cara pemetikan kopi sebagian besar dilakukan secara campuran $(45 \%)$ karena petani menghendaki kemudahan. Hal ini juga dilakukan oleh petani kopi di Kabupaten Rejanglebong Provinsi Bengkulu, yang sebagian besar petani melakukan panen secara pelangi/campuran (Afrizon dan Ishak, 2020). Fakta ini menunjukkan pada umumnya petani kopi belum menerapkan anjuran cara panen yang baik, padahal hasil penelitian Afrizon dan Ishak (2020) selanjutnya menyimpulkan dengan penerapan panen kopi petik 
merah dapat meningkatkan produksi kopi sebanyak $30 \%$ dan meningkatkan pendapatan petani sebanyak $\mathrm{Rp}$ 2.295.000 (51,4\%) dibandingkan dengan penerapan panen petik pelangi.

\section{Jumlah Produksi Kopi}

Jumlah kopi yang dihasilkan petani setiap tahunnya bisa mencapai $16.617 \mathrm{~kg}$ atau sekitar $923 \mathrm{~kg}$ per petani. Berdasarkan produksi kopi yang diperoleh yaitu rata-rata $923 \mathrm{~kg}$ per petani per tahunnya, maka jumlah tersebut sudah di atas produksi rata-rata nasional yaitu sebesar $802 \mathrm{~kg} / \mathrm{ha}$ (Kementerian Pertanian Republik Indonesia, 2018). Adapun untuk harga jual rata-rata kopi biji sebesar $\mathrm{Rp}$ 19.000/kg ini lebih rendah jika dibandingkan dengan harga jual rata-rata kopi biji di Kabupaten Tenggamus Provinsi Lampung yaitu sebesar Rp 21.000/kg ke pengepul (Justiceawan dan Apriyani, 2020). Namun harga tersebut lebih tinggi jika dibandingkan dengan harga jual rata-rata kopi biji di Kabupaten Bogor yaitu sebesar Rp 17.650/kg (Sumantri et al, 2020). Mengenai cara pembayaran kopi, pada ketiga kabupaten sebagaian besar adalah sama yaitu dengan sistem cash (pembayaran tunai).

\section{Pola Saluran Pemasaran Kopi}

$75 \%$ petani menjual hasil produksi kepada bandar desa/tengkulak/agen, 20\% menjual sendiri ke masyarakat sekitar, dan hanya $4 \%$ petani menjual kopi melalui media online. Proporsi ini mengarah kepada pola tataniaga kopi yang tidak efisien karena pembagian keuntungan yang jelas tidak adil (Mubyarto, 1989). Kondisi ini selaras dengan hasil penelitian Sugiarti (2010) yang menyimpulkan sistem pemasaran kopi di kecamatan Bermani Ulu Raya telah bekerja kurang efektif, artinya dapat menyalurkan kopi yang dihasilkan dari tingkat petani ke tingkat konsumen dengan lancar tetapi pasar dimana struktur pasar yang dihadapi adalah oligopsoni pada tingkat pedagang besar. Mengenai penjualan langsung ke tengkulak atau pengepul di atas juga selaras dengan penelitian Sumantri et al (2020) yang menyimpulkan penjualan kopi seluruh petani secara langsung kepada pengepul dan harganya ditentukan oleh pengepul.

\section{E. Proporsi Segmen Pemasaran Kopi}

95\% petani memasarkan kopinya ke wilayah lokal dan 5\% petani ke luar daerah (luar Kabupaten Kuningan). Kondisi ini berbeda dengan hasil penelitian Tuar dan Tamba (2019) yang 
menyimpulkan proporsi segmen pemasaran kopi sebesar $40 \%$ dijual kepada pedagang lokal dan sebanyak $60 \%$ kepada pedagang besar (industry) di Kabupaten Bangli Provinsi Bali. Perbedaan proporsi segmen pemasaran kopi ini dikarenakan kondisi daerah sentra produksi (produsen) dan sosial ekonomi petani yang juga berbeda.

\section{F. Pengolahan Kopi}

$53 \%$ petani mengolah kopi secara campuran yaitu tradisional dan modern, mulai dari pengolahan awal, roasting, penggilingan hingga pengemasan dan pemasaran. $27 \%$ petani mengolah secara tradisionil dan 20\% secara modern. Adapun cara pengolahan kopi di atas, yaitu: 1) Pengolahan awal kopi: Pengolahan awal seperti pengupasan, pengeringan, perendaman, fermentasi dan perambangan dilakukan dengan peralatan yang sederhana dan hasilnya menjadi green bean yang bervariasi yaitu full wash, natural, honey dan wine, sesuai dengan permintaan pasar (Santani, 2018; Arvian et. al, 2018); 2) Roasting: bertujuan membentuk rasa asli dari biji kopi dan ada tiga tingkat kematangan, yaitu light, medium, dan dark roast (Santani, 2018); (Arvian et al, 2018), $69 \%$ petani melakukan roasting dengan menyewa jasa roasting, selebihnya pengolah melakukan roasting sendiri; 3)

Penggilingan: Penggilingan kopi dilakukan oleh pengolah kopi sendiri ataupun menggunakan jasa sewa penggilingan kopi; 4) Pengemasan: pengemasan kopi umumnya dilakukan sendiri dengan kemasasan yang bervariasi, mulai dari kemasan sederhana berupa plastik bening hingga kemasan aluminium foil; 5) Pemasaran: pemasaran kopi hasil olahan dilakukan melalui berbagai cara, antara lain: dijual langsung di tempat, dititipkan ke toko oleh-oleh, dijual melalui resealer atau dijual ke tengkulak.

\section{G. Aneka Penyajian Minuman Kopi}

Beberapa aneka bentuk penyajian minuman kopi, antara lain: kopi tubruk, espresso, Vietnam drip, aero press, Americano, red eye, moka pot, V-60 dan sebagainya (Samsura, 2012); (Arvian et al, 2018); Samsura, 2018). Adapun bentuk penyajian yang paling disukai konsumen di lokasi penelitian, yaitu latte artsebesar 47\%, kemudian V-60 (13\%), Vietnam Drip (13\%), kopi tubruk (13\%), manual (7\%) dan mix blended (7\%).

\section{H. Kepedulian Konsumen Kepada Petani Kopi}

Tingkat kepedulian kosumen terhadap petani kopi di Kabupaten Kuningan terutama mengenai asal-usul 
dan kualitas kopi, masih bervariasi, yaitu sebanyak 37\% konsumen kopi peduli, $27 \%$ konsumen cukup peduli, $18 \%$ konsumen sangat peduli, dan $18 \%$ konsumen tidak peduli. Bentuk kepedulian dari konsumen kopi terhadap petani kopi baru diwujudkan dalam komentar atau sikap kesediaan untuk membeli atau mengkonsumsi kopi lokal dan mempromosikannya kepada daerah sendiri dan daerah lain.

\section{Jumlah Petani Kopi}

Kopi yang diminum oleh konsumen atau penikmat kopi, dengan berbagai jenis, kualitas dan cita rasa kopi yang khas, tidak terlepas dari adanya jerih payah petani kopi di perdesaan (Santani, 2018; Arvian et al 2018). Petani kopi yang ada di Kabupaten Kuningan tersebar di beberapa wilayah besar (sentra produksi), antara lain: di Kecamatan Subang, Darma dan Mandirancan. Jumlah petani pada saat ini cenderung terus bertambah selaras dengan trend pengembangan luas kebun kopi di Provinsi Jawa Barat yang naik dari tahun 2014-2018 (Kementerian Pertanian Republik Indonesia, 2018), pertumbuhan permintaan kopi dalam negeri sendiri selama periode tahun 2016-2019 cukup tinggi yaitu sebesar $17,6 \%$ yang disebabkan oleh permintaan produk kopi siap minum dan perluasan gerai ritel kopi (Donald, 2019). Selain itu, juga dikarenakan nilai tambah pada pengolahan kopi yang menguntungkan (Dewi et. al, 2015; Surya dan Sudarma, 2016). Pada saat ini jumlah petani kopi mencapai 3.116 orang dan ini mengalami penambahan yang cukup tinggi jika dibandingkan 5 tahun yang lalu. Kondisi yang demikian juga sangat berbeda jauh dengan kondisi pada tahun 2007 dimana permintaan kopi lokal sangat menurun (Kustiari, 2007).

\section{J. Tumbuhnya Kedai-Kedai Kopi (Coffee Shop)}

Selaras dengan semakin banyaknya konsumen kopi dan sejalan dengan semakin banyaknya konsumen yang menghargai (peduli) terhadap kopi lokal serta trend pertumbuhan kedai kopi (coffee shop) nasional yang naik $143 \%$ pada dekade ini (Toffin, 2020), telah berdampak juga pada tumbuhnya kedai kopi di Kabupaten Kuningan. Penyebab pertumbuhan kedai kopi selaras dengan adanya perubahan gaya hidup terutama kaum muda yang minum kopi di kedai kopi pada era sekarang bukan hanya sekedar minum tetapi sudah merupakan gaya hidup kekinian. Hal ini selaras dengan penelitian Alfirahmi (2019) yang menyimpulkan upaya yang ditempuh 
oleh gerai kopi di Indonesia menjamur bahkan menjadi bagian dari gaya hidup kaum urban dan pemasaran 4.0 yang menyatukan sistem offline dan online menjadi alasan bagi gerai kopi untuk semakin menarik kaum urban lebih mengenal dan mengkonsumsi kopi.

Pertumbuhan kedai kopi di Indonesia yang pesat dewasa ini, telah berdampak munculnya barista-barista sebagai profesi yang penting dalam mendukung keberadaan kedai kopi modern (coffee shop). Barista merupakan orang yang mempunyai keterampilan dalam meracik secangkir kopi, mengenal karakter rasa kopi yang digunakan, proses penanamanannya hingga asal kopi tersebut (Sidewalk, 2019). Panggabean (2012) menambahkan bahwa ada tiga seni yang harus dikuasai oleh seorang barista, yaitu seni melayani, menyajikan, dan meracik kopi di sebuah café (kedai kopi). Barista yang professional mempunyai peran yang strategis dalam menghubungkan kepentingan subsistem hulu, subsistem pengolahan dan subsistem hilir dalam konsep pengembangan agribisnis kopi di Indonesia atau dalam turut mewarnai pemasaran kopi pada era ketiga. Pentingnya keberadaan barista di coffee shop sangat berkaitan dengan perannya dalam hal pelayanan yang prima kepada konsumen dapat mengulang untuk membeli lagi (kepuasan konumen). Hal ini sesuai dengan hasil dari beberapa penelitian yang menyatakan pelayanan barista sangat berpengaruh terhadap kepuasan konsumen (Mu'tashim, 2019), kualitas pelayanan menjadi kelebihan dari kedai kopi JSL (Evania, 2020) dan kualitas pelayanan berpengaruh positif terhadap kepuasan pelanggan (Kentzi, dkk., 2020).

\section{KESIMPULAN DAN SARAN}

Pemasaran kopi pada era ke tiga di Kabupaten Kuningan belum tersinergi antara subsistem hulu, subsistem pengolahan dan subsistem hilir, sehingga indikator-indikatornya belum terpenuhi secara optimal, yang mengakibatkan peluang manfaat (laba) atau nilai tambah yang ada dalam agribisnis kopi ini belum diperoleh secara proporsional diantara subsistem, terutama pihak petani yang selalu mendapat proporsi rendah.

Hasil penelitian ini menghasilkan saran (implikasi kebijakan) untuk Pemerintah Kabupaten Kuningan Provinsi Jawa Barat terutama pada sub sektor perkebunan yaitu adanya tindak lanjut dari Pemerintah Kabupaten Kuningan cq. Dinas Perkebunan untuk 
memprakarsai sinergitas diantara subsistem ( sub sistem hulu, sub sistem pengolahan dan sub sistem hilir) dalam pengembangan agribisnis kopi yang saling menguntungkan dan berkelanjutan.

\section{UCAPAN TERIMAKASIH}

Ucapan terimakasih yang sebesarbesarnya disampaikan kepada Kementerian Pendidikan dan Kebudayaan Republik Indonesia yang telah mendanai penelitian ini pada TA. 2019/2020.

\section{DAFTAR PUSTAKA}

Adhi Prakosa. (2019). Generasi third wave coffee: Perspektif milenial terhadap kopi gelombang ketiga. The Journal of Business and Management, 2(2), 106-118. https://doi.org/https://doi.org/10.37 112/bisman.v2i2.443

Afrizon Afrizon, Andi Ishak. (2020). Upaya peningkatan produksi kopi dengan panen petik merah di kabupaten Rejang Lebong. Agritepa, 7(1), 31-40. https://doi.org/10.37676/agritepa.v7 i1.1001

Alfirahmi. (2019). Fenomena kopi kekinian di era 4.0 ditinjau dari marketing 4.0 dan teori uses and effect. Jurnal Lugas, 3(1), 24-32. https://doi.org/https://doi.org/10.31 334/ljk.v3i1.410

Annisa Marchantia Pratiwi, Hari Kaskoyo, Susni Herwanti, R. Q. (2019). Saluran pemasaran kopi robusta (coffea robusta) di agroforestri pekon air kubang, kecamatan air naningan, kabupaten tanggamus. Jurnal Belantara, 2(2), 76-81.

https://doi.org/https://doi.org/10.29 303/jbl.v2i2.183

Doddy Samsura. (2012). Ngopi ala barista (1st ed.). Penebar Plus. https://bit.ly/3dhCXOf

Doddy Samsura. (2018). Ngopi yuk! Bisnis dan sajian kopi ala kafe (1st ed.). Panebar Plus. https://bit.ly/3dfRkST

Donald, A. R. and G. M. (2019). Indonesia Coffee Annual Report 2019. https://bit.ly/3s4Hojf

Edy Panggabean. (2012). The Secret of Barista (1st ed.). PT WahyuMedia. https://bit.ly/3uNmmaX

Egristofer Evander Tuar, I Made Tamba, P. F. K. L. (2019). Analisis pemasaran kopi arabika di Desa Belantih Kecamatan Kintamani Kabupaten Bangli. Agrimeta, 9(18), 10-14. https://ejournal.unmas.ac.id/index.php/agri meta/article/view/634

Elly Rasmikayati, Pandi Pardian, Hepi Hapsari, Risyad M. Ikhan, B. R. S. (2017). Kajian sikap dan perilaku konsumen dalam pembelian kopi serta pendapatnya terhadap varian produk dan potensi kedainya. Pemikiran Masyarakat Ilmiah Berwawasan Agribisnis, 3(2), 117133.

https://jurnal.unigal.ac.id/index.php /mimbaragribisnis/article/view/563

Elvin Desi Martauli. (2018). Analysis of coffee production in indonesia. Journal of Agribusiness Science, l(2), 112-120. https://bit.ly/3wTKYjS

Evania, E. (2020). Analisis kualitas pelayanan terhadap kedai kopi independen "JSL COFFEE." In Podomoro University. http://repository.podomorouniversit y.ac.id/id/eprint/117

H. Rahmat Rukmana dan Sigit Suyantoro 
FI. (2014). Untung selangit dari agribisnis kopi (Fl. Sigit Suyantoro (Ed.); 1st ed.). Lily Publisher. https://bit.ly/3sfUGtv

International coffee organization. (n.d.). http://www.ico.org/show_news.asp ?id $=705$

Jef Rudiantho Saragih. (2017). Aspek sosioekologis usahatani kopi arabikadi dataran tinggi kabupaten simalungun Sumatera Utara. Sosiohumaniora, 19(3), 253-259. https://doi.org/https://doi.org/10.24 198/sosiohumaniora.v19i3.7896

Kementerian Pertanian Republik Indonesia. (2018). Sub-sektor perkebunan (estate crops subsektor).

https://www.pertanian.go.id/home/? show $=$ page $\&$ act $=$ view $\&$ id $=61$

Kentzi, Innocentius Bernarto, D. W. (2020). Pengaruh pelanggan dan kualitas layanan terhadap kepuasan dan dampaknya terhadap loyalitas pelanggan maxx coffe benton junction Lippo Karawaci, Tangerang, Banten. Hospitaliti Dan Pariwisata, 3(1). https://doi.org/https://doi.org/10.35 729/jhp.v3i1.38

Kotler, P. (2000). Prinsip - prinsip pemasaran manajemen. Prenhalindo.

Marilyn Johnson-Kozlow, Donna KritzSilverstein, Elizabeth BarrettConnor, and D. M. (2002). Coffee Consumption and Cognitive Function among Older Adults. American Journal of Epidemiology, 156(9), 842-850. https://doi.org/10.1093/aje/kwf119

Mohammad Welly Justiceawan, Marlinda Apriyani, F. M. S. (2020). Analisis efesiensi tataniaga kopi di Desa Ngarip Kecamatan Ulubelu Kabupaten Tanggamus. Journal of Food System \& Agribusiness, 4(1), 17-24. https://doi.org/https://doi.org/10.25 181/jofsa.v4i1.1518

Mubyarto. (1989). Pengantar Ekonomi Pertanian (3rd ed.). LP3ES. https://bit.ly/3dj5anE

Mush'ab Ihsan Mu'tashim, A. S. S. (2019). Pengaruh kualitas produk dan kualitas pelayanan terhadap kepuasan konsumen (studi kasus pada coffee shop di Kota Bogor). Manajemen Dan Organisasi, 10(2), 118-132.

https://doi.org/https://doi.org/10.29 244/jmo.v10i2.30131

Ni Luh Made Indah Murdyani Dewi, I Wayan Budiasa, I. A. L. D. (2015). Analisis finansial dan nilai tambah pengolahan kopi arabika di koperasi tani manik sedana Kabupaten Bangli. Agribisnis Dan Agrowisata, 4(2), 97-106. https://ojs.unud.ac.id/index.php/JA A/article/view/17392/11422

Ni Luh Wicanodian Surya, I Made Sudarma, P. U. W. (2016). Nilai tambah dan kelayakan usaha pengolahan kopi arabika pada unit usaha produktif Ulian Murni Kabupaten Bangli. Agribisnis Dan Agrowisata, 5(1), 1-10. https://ojs.unud.ac.id/index.php/JA A/article/view/18659/12124

Nia Rosiana. (2020). Dinamika pola pemasaran kopi pada wilayah sentra produksi utama di Indonesia. Jurnal Agrosains Dan Teknologi, 5(1), 1-10.

Pudji Raharjo. (2012). Kopi panduan budidaya \& pengolahan kopi arabika dan robusta (Trias QD (Ed.); 1st ed.). Penebar Swadaya. http://www.penebar-swadaya.com

Reni Kustiari. (2007). Market development of world coffee and its implication for Indonesia. FORUM PENELITIAN AGRO EKONOMI, 25(1), 43-55. https://bit.ly/3uPm96P 
Santani, D. H. \& A. (2018). Coffee: Karena selera tidak dapat diperdebatkan (2nd ed.). AgroMedia Pustaka. https://bit.ly/2R19TN3

Sugiarti, S. (2010). Analisis pemasaran kopi di Kecamatan Bermani Ulu Raya Kabupat. Jurnal AGRISEP, 9(2), $130-136$ https://doi.org/10.31186/jagrisep.9. 2.130-136

Sugiyono. (2015). Metode penelitian kuantitatif, kualitatif dan kombinasi (mixed methods) (1st ed.). Alfabeta. http://opac.ut.ac.id/detailopac?id=33096

Sumantri, S., Yusdiarti, A., \& Miftah, H. (2020). Studi kelayakan investasi kopi robusta (coffea canephora). AgribiSains, 6(1), 39-49. https://doi.org/DOI:10.30997/jagi.v $6 \mathrm{i} 1.2805$

Tim Karya Tani Mandiri. (2010). Pedoman Budi Daya Tanaman Kopi (1st ed.). Nuansa Aulia. https://onesearch.id/Record/IOS134 02.INLIS000000000764011
Tjiptono, F. (2008). Strategi Pemasaran (3rd ed.). Andi Offset. https://bit.ly/3dbx3y4

Toffin. (2020, July 12). https://toffin.id/riset-toffin/. Sindo News, 1. https://toffin.id/risettoffin/

Wachdijono, Umi Trisnaningsih, S. W. (2019). Analisis preferensi konsumen kopi pada era revolusi industri 4.0. Agriekonomika, 8(2), 181-193. https://doi.org/10.21107/agriekono mika.v8i2.5427

Willy Sidewalk. (2019). Barista \#No cingcong shut up \& brew (1st ed.). AgroMedia Pustaka. https://agromedia.net/katalog/barist a-nocingcong/

Yandhrie Arvian et. al. (2018). Kopi: Aroma, rasa, cerita (1st ed.). Tempo. https://bit.ly/3dWOphe 